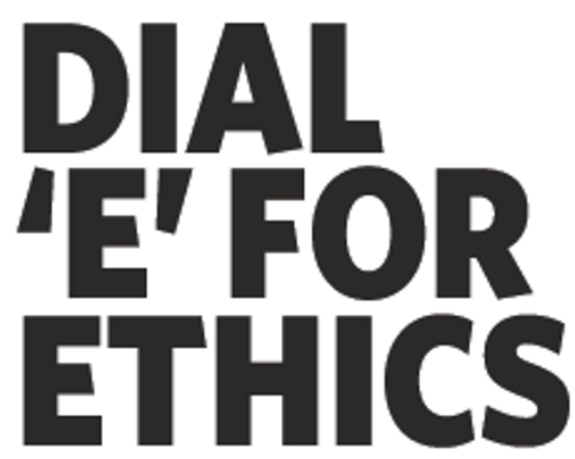

Facing a moral dilemma in the lab? No reason to panic. Helen Pilcher meets the academic troubleshooters who promise a quick answer to any ethical problem.

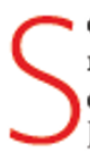
ometimes you're midway into a research project before an ethical dilemma reveals itself. This was Joachim Hallmayer's experience at the Stanford School of Medicine in California. About a year after he and his team had begun recruiting children for a genetic study of autism, they realized that they couldn't agree what results to share with the parents. "It's sometimes difficult to know what information will be useful and what will be dangerous," admits Hallmayer, a psychiatric geneticist.

But the team was in luck. Across campus, at the Stanford Center for Biomedical Ethics, a pilot project offering biomedical researchers speedy practical advice on ethical concerns was under way. Hallmayer contacted the 'dialan-ethicist' project, or bench-side consultation service as it is also known, and three weeks later got professional answers to his questions.

Hallmayer's team is now pursuing its autism study with a renewed sense of harmony. But the Stanford service aims to go beyond ethical troubleshooting, say co-founders David Magnus and Mildred Cho. "A lot of scientists don't really see ethics as a part of their job," says Cho. By making the usually academic field of bioethics more accessible, Magnus and Cho hope to promote a culture of ethical thinking within the laboratory.

Often scientists don't think about ethics until it is too late - sometimes when their research has already hit the headlines. In South Korea, disgraced stem-cell pioneer Woo Suk Hwang not only fabricated results, he also obtained eggs from women donors under questionable circumstances. And he did it all while claiming to follow ethical guidelines. It's an extreme example of the harm that can be caused when ethics advice is ignored, but one

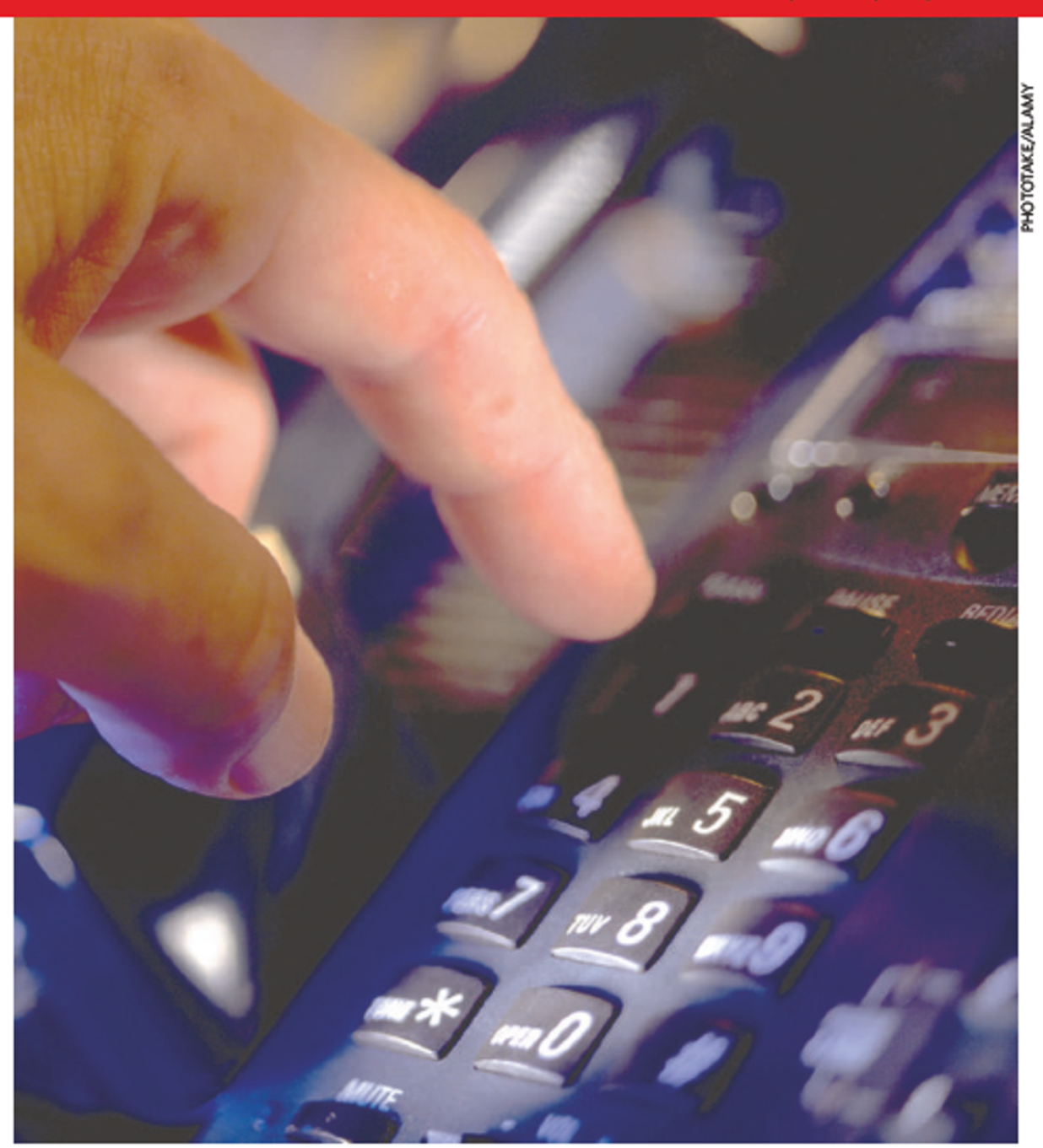

Stanford biomedical researchers can now phone a friend to discuss their pangs of conscience.

that raises questions about the role of bioethicists in the laboratory.

Some people doubt whether practical ethics advice can make a real difference. Can bioethicists retain credibility when their advice is sought but ignored? Are they liable when things go wrong? And what about claims that they rubber-stamp most research proposals?

"Bench-side consultations are a way of integrating ethical thinking into a scientist's everyday life," says Magnus, director of the Stanford centre. Like most of his colleagues he doesn't think bioethicists should be expected to prevent misconduct. But he believes his benchside service can foster integrity in trainee scientists and so indirectly prevent research going off the ethical rails.

The Stanford service is designed to help researchers identify the ethical and social issues that arise in their work and aims to complement, not replace, the bodies that regulate human and animal studies. Institutional review boards (IRBs), for example, oversee all federally funded US biomedical human studies. They evaluate the risks and benefits to people who participate, from their recruitment through to the confidentiality of results.
An IRB seal of approval must be in place before a study begins.

Unlike IRB approval, the Stanford service is voluntary, not mandatory, and it yields confidential advice, rather than edict. The Stanford team will advise researchers at any point in a study, although they prefer to be involved at the start. The pilot seeks to address issues, such as the broader societal implications of a study, that go beyond the scope of IRBs. In fact, the project was set up, in part, to offer advice on human embryonic stem-cell research, which initially fell outside the IRB's purview.

\section{Brisk business}

Over the past six months, the pilot service has given consultations to seven different Stanford research groups. Topics ranged from oncology trials to microarray analysis, and the ethical issues from conflicts of interest to what to do with incidental findings. Six of the queries were easily resolved, most within 24 hours, and half of the responses involved alerting researchers to existing rules rather than developing new policies.

Hallmayer's request, however, required deeper analysis. The California Autism Twin Study (CATS) plans to assess 300 twin pairs on a range of skills, including intelligence, language and planning ability. To date, more 
$y$ than 60 pairs of children have been recruited and around a dozen tested. But as the data trickled in, ethical concerns grew about how much to tell the parents about the test results.

This is partly because the CATS tests can differ from those used by psychiatrists to diagnose autism and are administered by trained researchers rather than clinicians. Such nonclinical test results raise several problems. A presumed autistic child could, for example, test normal, or a normal sibling could display mild, sub-clinical problems. DNA tests designed to check whether twins are identical or not, and to exclude children with the inherited mental impairment, fragile X syndrome, create their own problems. A positive fragile X result would suggest one parent is carrying the causal mutation, for example.

\section{Should we tell them?}

Any such findings could have repercussions for family dynamics, insurance and state benefits, and so Hallmayer felt it wise to tell parents less rather than more. ${ }^{\alpha}$ They may have a right to know, he says, "but the results can give a child a label that is unnecessary and meaningless." Others on the team, however, felt it was wrong to withhold findings from parents.

Hallmayer contacted the Stanford ethics service last year. He and his team discussed their problems with four consultants, including Cho and Magnus. Three weeks later, they received a written list of recommendations.

The ethics team concluded that because the test results do not indicate a treatable or preventable life-threatening condition, researchers are not required to inform the par-

ents. Non-clinical test results

should not be disclosed, they advised, but other results can be shared if the parents want to know. Positive fragile $\mathrm{X}$ tests should always be replicated in a dinical laboratory, and parents should be made aware of the possible implications for insurance and employment.

The CATS team tweaked its study design, received additional IRB approval, and pursued its study. Both Hallmayer and the Stanford ethicists are pleased with the outcome. But the bench-side experience is not always a happy one.

Bioethicist Insoo Hyun, from Case Western Reserve University in Cleveland, Ohio, spent three months in summer 2005 in Hwang's laboratory studying the cultural, social and legal implications of the Korean stem-cell research. Healso helped to fine-tune Hwang's informedconsent procedure for egg donation, publishing a paper reporting the procedure in The American Journal of Bioethics (K. W. Jung and I. Hyun Am. J. Bioeth. 6, W19-W22; 2006). When he learned in December that Hwang had not followed the procedure he felt angry,

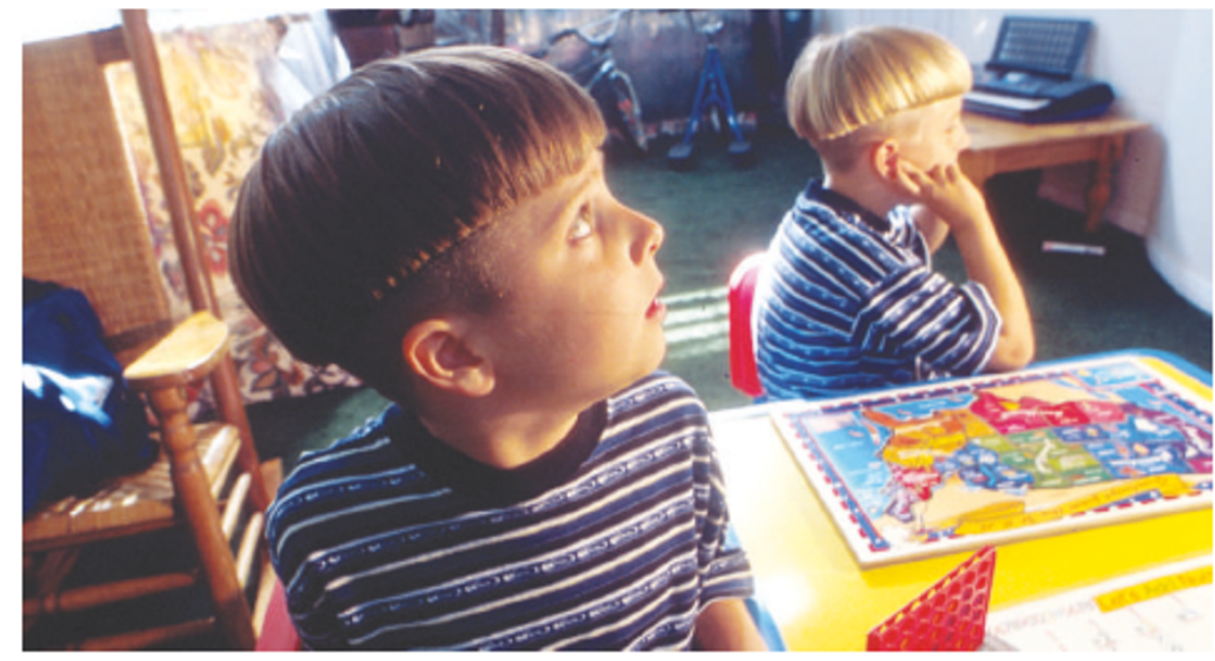

Parents may be better off not knowing the findings of studies on their autistic children.

saddened and betrayed.

Hwang seems to have obtained independent advice from at least two ethicists in addition to IRB approval for his research. But he violated ethical guidelines by collecting eggs from laboratory juniors and other donors who were not warned of possible side effects.

About 20 of the donors have developed side effects including abdominal pain, diarrhoea and vomiting. And their eggs contributed to research that now appears to have been faked. The kindness of the donors has been exploited, patient hopes shattered, and public confidence in stem-cell research is in tatters.

The scandal underscores the perils of ignoring ethical advice. But it also highlights the limitations of ethical consultations in the laboratory. Hyun and his coauthor had to retract their paper when it became clear that Hwang had ignored their recommendations (G. McGee, Am. J. Bioeth. 6, W33; 2006). "My experience with Hwang has changed my attitude to getting involved with other labs," says Hyun.

In future, Hyun says he would be more sceptical. Magnus, who has also written about the ethics of egg donation, believes that the ethicists in Hwang's lab did little to find ethical flaws. "I am concerned that too many of the bioethicists there were cheerleaders, "he says.

In his defence, Hyun says, bioethicists view themselves as pilots through treacherous waters. "Being an ethical consultant doesn't put you in a position to prevent misconduct," he says. Consultants presuppose that researchers have the integrity to take their advice seriously. "If people are out to deliberately deceive you, there's nothing you can do"

Some view all ethical oversight with suspicion. Bioethicists merely provide the veneer of a job well done, says Vera Sharav, president of the Alliance for Human Research Protection, New York, a watchdog organization that seeks to expose unethical research practices. Most, she believes, issue ethical approval too easily and fail to offer truly independent advice.

But Ronald Green, a bioethicist from the Dartmouth College Ethics Institute, Hanover, New Hampshire, finds generalized accusations of 'bioethics for hire' preposterous. Green chairs the ethics advisory board at Advanced Cell Technology, a US-based biotechnology company developing stem-cell therapies. Any payment to ethicists is a minimal daily stipend, and with ethical advice carrying no weight in law, 'buying it' simply doesn't make sense, he says. For his part, Hyun believes his relationship with Hwang was sufficiently independent, with funding from a Fulbright scholarship, to allay such concerns.

\section{Blowing the whistle}

What would the Stanford ethicists do if they discovered research that was illegal or breached public health and safety? Although they sign confidentiality agreements with Stanford researchers, Magnus and Cho say they have an obligation to report misconduct if they come across it. But what about less serious transgressions? "I don't think bioethicists should be policing research," says Magnus.

To avoid potential criticisms, the Stanford team is financially independent thanks to federal funding. The service is now being offered to all biomedical researchers at Stanford; other institutions, including Case Western Reserve University and Duke University in North Carolina, are setting up similar bench-side consultations. Hyun is not involved in the Case Western service at present, although he has not ruled that out. The hope is that such a service will promote ethical awareness in the lab. It's not a watchdog, but it must avoid looking like a show dog. It might not prevent deliberate misconduct, but it should help researchers who want to do the right thing.

Helen Pilcher is a freelancer based in

Not tinghamshire, UK. 